\title{
Steps toward a resilient circular economy in India
}

\author{
Joseph Fiksel ${ }^{1}$ [D $\cdot$ Praveena Sanjay $^{2} \cdot$ Kavya Raman $^{3}$
}

Received: 29 September 2020 / Accepted: 30 October 2020 / Published online: 11 November 2020

(c) Springer-Verlag GmbH Germany, part of Springer Nature 2020

\begin{abstract}
Developing nations, including India, face a number of daunting challenges in the twenty-first century, including population growth, political strife, rapid urbanization, food and water scarcity, environmental pollution, infectious diseases, and climate change. In this turbulent era, there is a need for resilience at every level—from the village family to the corporate boardroom to the halls of government. We argue that achieving resilience will require both enlightened government policies and successful initiatives by social and environmental innovators that demonstrate the capacity for adapting to these challenges. Such practical first steps can serve as models for creating a more resilient and sustainable economy in India. One way to stimulate rapid progress is development of circular economy solutions that create innovative pathways for utilization of discarded materials, thus seeking to eliminate waste. Previous research has shown that such initiatives reduce environmental pressures and improve community resilience, while stimulating the regional economy. An international conference on Waste Management Innovation, held in 2017 in Mumbai with funding from the US Consulate General, resulted in the award of seed grants to two Indian non-profits that sought to apply circular economy principles to regional communities—one urban and one rural. These initiatives provide case studies of circular economy implementation. The World Institute of Sustainable Energy has developed an action plan to capture at least 60 percent of the electronic waste generated in the city of Pune, one of the largest metropolitan areas in India. Their approach is based on circular economy principles, and has been embraced in stakeholder meetings with city officials as well as local residents and non-governmental organizations. Barefoot College has established and demonstrated a low-cost, end-to-end solid waste management model for rural villages that is designed by the local community. Their unique approach ensures sanitation, environmental protection, income and livelihood generation, and drives behavioral change in village residents by motivating them to maintain community hygiene. This paper presents the results of these two efforts, and suggests what lessons were learned. One overarching insight is that an integrated systems view is necessary to understand the interplay of economic, environmental, and social forces.
\end{abstract}

Joseph Fiksel

fiksel.2@osu.edu

Praveena Sanjay

praveena.ccs@wisein.org

Kavya Raman

kavyaraman8@gmail.com

The Ohio State University, Columbus, OH, USA

2 World Institute of Sustainable Energy, Pune, Maharashtra, India

3 Social Work and Research Centre, Barefoot College, Tilonia, Rajasthan, India 


\section{Graphic abstract}

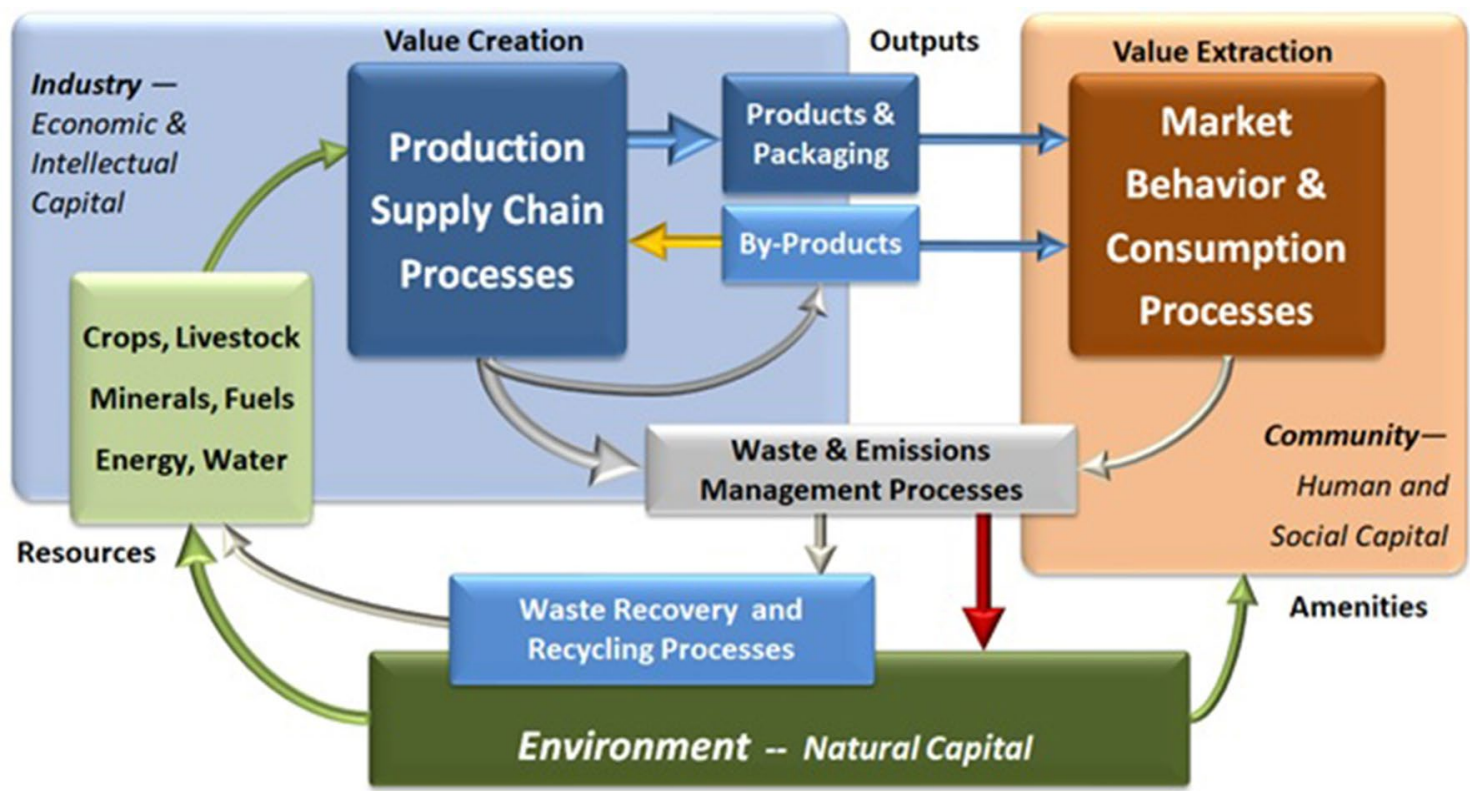

Keywords Resilience $\cdot$ Waste $\cdot$ Circular economy $\cdot$ Sustainable development $\cdot$ Systems thinking $\cdot$ India

$\begin{array}{ll}\text { Abbreviations } \\ \text { CPCB } & \begin{array}{l}\text { Central Pollution Control Board } \\ \text { Civil Society Organization }\end{array} \\ \text { CSO } & \begin{array}{l}\text { Ministry of Electronics and Information } \\ \text { MeitY }\end{array} \\ \text { Technology } \\ \text { MoEFCC } & \begin{array}{l}\text { Ministry of Environment, Forest and Climate } \\ \text { Change }\end{array} \\ \text { MPCB } & \text { Maharashtra Pollution Control Board } \\ \text { NGO } & \text { Non-governmental Organization } \\ \text { NGT } & \text { National Green Tribunal } \\ \text { PMC } & \text { Pune Municipal Corporation } \\ \text { PRO } & \begin{array}{l}\text { Producer Responsibility Organization } \\ \text { SDGs }\end{array} \\ & \text { Sustainable Development Goals }\end{array}$

\section{The need for resilience}

In recent years, the rapid growth of the Indian economy has been accompanied by an array of social and environmental stress factors, including population growth, political strife, rapid urbanization, food and water scarcity, environmental pollution, and climate change. By 2050, half of India's population will live in cities, and municipal solid waste volume is expected to triple to about 436 million metric tons (MT) (Lal 2013). While India has committed to the UN Sustainable Development Goals (SDGs), termed the Agenda 2030 (U.N. 2015), progress is hampered by haphazard urban development and ineffective regulatory controls. Moreover, the focus on long-term sustainability is often trumped by social and political turbulence, as well as unexpected disruptions such as terrorism, industrial accidents and extreme weather events. Most recently, the COVID-19 pandemic has dealt a severe blow to the health and safety of India's diverse population, as well as to India's burgeoning economy. Unfortunately, the adverse impacts of these stress factors will disproportionately affect the informal sectors of the economy where hundreds of millions of lower-caste workers struggle to support themselves and their families.

In this time of disruptive change, there is a clear need for resilience at every level—from the peasant family to the corporate boardroom to the halls of government. We define resilience as "the capacity for a system to survive, adapt, and flourish in the face of turbulent change and uncertainty" (Fiksel 2015). In the context of economic development, the "system" is extremely complex, since it involves producers, supply chains, consumers, waste handlers, regulators, and non-governmental organizations that may be located in different geographic zones. Moreover, a true systems view must consider the social and environmental consequences of remaining in the current state, the potential benefits to various stakeholders of proposed adaptations, and the accompanying uncertainties.

Resilience is often confounded with sustainability. The two concepts are closely related, but quite different in scope and time scale. Sustainability represents a long-term view, considering how decisions that we make today will influence 
the well-being of both present and future generations. It is based on an idealistic view of productive harmony between humans and the environment. Resilience is a more pragmatic, real-time concept-considering how to overcome unexpected disruptions while building an organization or community that embraces change.

Generally speaking, we can say that a sustainable system is more resilient to disruptions and a resilient system is more sustainable in the long run. In other words, sustainability and resilience are distinct but mutually reinforcing. However, sustainability and resilience may not always be synergistic. There are situations where sustainability and resilience are opposing rather than reinforcing. For example, by storing backup supplies, a company may improve business continuity but this also increases the environmental footprint. In the Indian context, we argue that both resilience and sustainability can be achieved by a combination of enlightened government policies based on systems thinking, as well as successful initiatives by social and environmental innovators. These practical first steps can serve as models to be replicated, thus defining a path forward toward a resilient and sustainable Indian economy.

\section{Waste management challenges in India}

For purposes of achieving both sustainability and resilience, a critical area that must be addressed in India is the management of municipal, industrial and agricultural wastes in both urban and rural areas. As of 2016, urban areas in India, representing about 377 million people, generated 62 million MT of municipal solid waste each year. Of this, only about $70 \%$ are collected due to insufficient municipal services. About $20 \%$ of the collected wastes are treated, and the remaining 50\% are disposed in open landfills, without proper treatment or containment. Based on changing consumption patterns and rapid economic growth, urban municipal solid waste generation is projected to reach 165 million MT by 2030. (India Environment Portal 2016).

In rural areas, agricultural wastes including crop and animal residues are often burnt in the fields or used as traditional household fuels. These practices have resulted in severe pollution of air, soil and water, creating health problems for both workers and nearby households. Recycling and composting programs are unable to keep pace with the growth of waste, although small startup companies and NGOs are introducing new solutions ranging from high-tech waste processing to improve training and support for waste picker communities (Fiksel and Lal 2018).

In theory, much of this waste could be beneficially used as renewable energy or materials. However, the challenges of modernizing waste collection, segregation, treatment and disposal are enormous. Following the establishment of the
Swachh Bharat (Clean India) Mission in 2014, a series of more stringent rules were issued in 2016 for solid waste management, including specific requirements for plastic wastes, electronic wastes, construction and demolition debris, biomedical wastes, and hazardous wastes. However, despite these regulatory efforts, the Indian economy will continue to generate growing waste streams due to increase in population, urbanization, crops and livestock, resulting in significant human health and environmental impacts.

For India to achieve continued economic growth, poverty alleviation, hunger elimination, human development, and environmental improvement, new transformative solutions are needed rather than incremental improvements. Beyond the obvious concerns about waste proliferation, improved waste management is important for controlling a significant source of greenhouse gases (GHGs) - methane emissions from landfills, as well as nitrous oxide and methane from agricultural waste combustion. Moreover, material throughput is a major driver of GHG emissions, and hence waste reduction will significantly decrease energy and material demand and the associated GHG emissions throughout global supply chains (Fiksel 2011).

This paper describes the results of a conference on Waste Management Innovation held in Mumbai in April 2017, with the purpose of stimulating waste minimization strategies based on "circular economy" principles (OSU 2017). The conference was sponsored by the US Consulate in Mumbai, which offered seed grants to non-profit organizations for demonstration of innovative approaches. The accomplishments of two grantee organizations are described belowone in an urban context and the other in a rural context.

\section{Circular economy opportunities}

The concept of "circular economy" as a strategy for waste elimination has been broadly adopted in the business world. Companies have sought to achieve "zero waste" by finding uses for discarded materials and closing the loop in their supply network. Circularity not only offers economic benefits and reduces a company's ecological footprint, but also increases both business and community resilience by reducing dependence upon scarce resources and long-distance supply chains. The concept has been implemented by progressive business leaders as a cost-effective means of improving corporate sustainability and resilience (Ellen MacArthur Foundation 2017).

The practice of circular economy requires a systems approach that considers the broader economic, social and environmental systems in which commercial supply chains operate. Figure 1 shows how a systems approach can be used to model the generation and disposition of wastes throughout the business value chain; this approach is based 


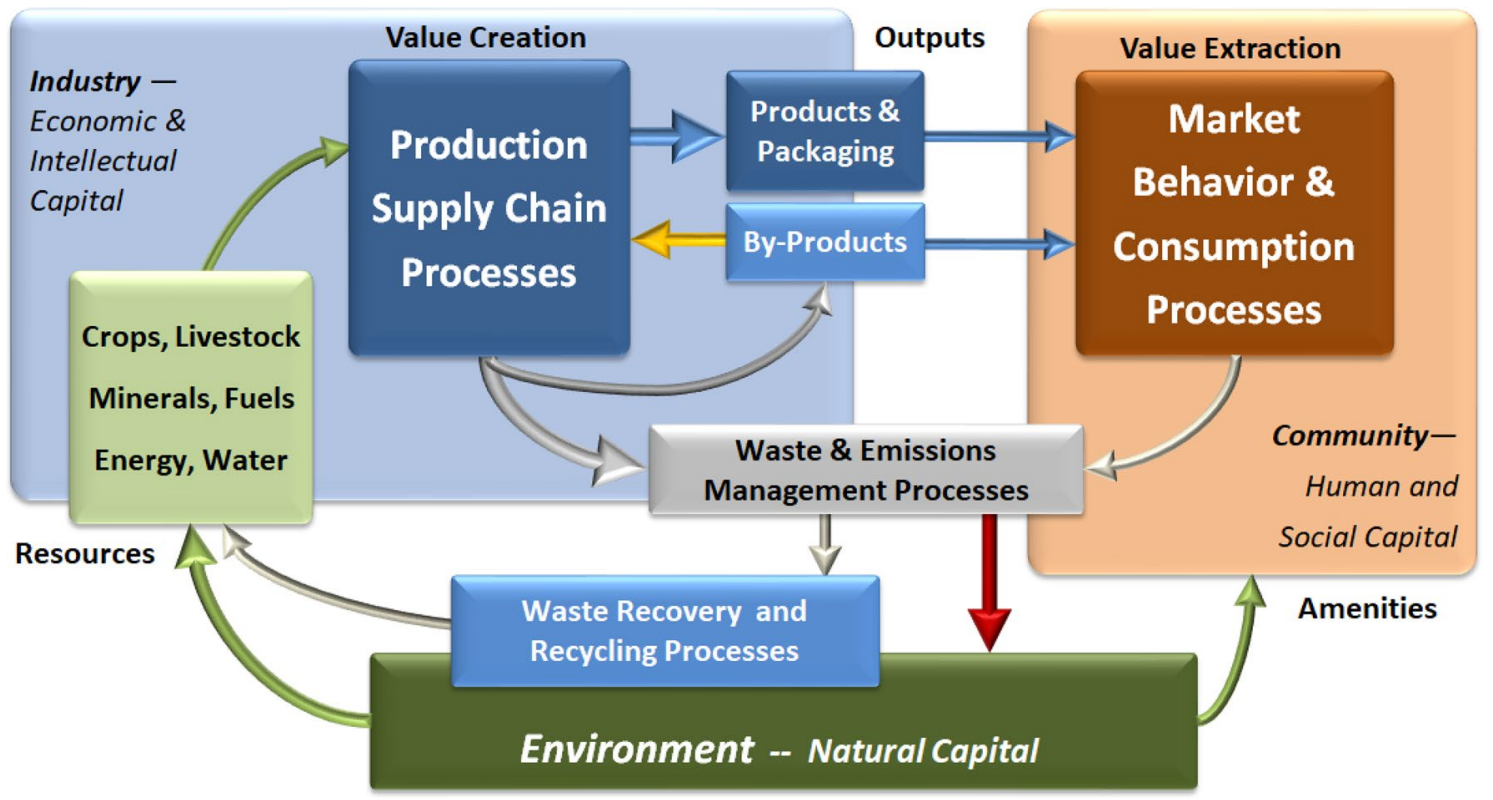

Fig. 1 A Systems View of Circular Economy Processes

on the triple value framework, which explicitly maps the interdependencies among three types of dynamic systemsindustries, communities, and the environment (Fiksel et al. 2014). Resources are extracted from the environment, move through production processes to create value for markets, and then the wastes are disposed or recycled. The lifecycle stages shown in Fig. 1 include extraction of raw materials from terrestrial sources, transport, processing, manufacturing and packaging into finished products, distribution and product support through various market channels, consumer use of products, and final disposal or recycling of the residual wastes. These wastes are generated in solid, liquid, and gaseous forms, and may include hazardous pollutants and greenhouse gases. In this type of holistic analysis, it is important to account for direct consequences, such as financial benefits, as well as indirect or unintended consequences, including environmental and social impacts.

The circular economy strategy envisions that industrial and consumer wastes can replace virgin materials-so that inefficient and harmful waste disposal is essentially eliminated. Many existing waste streams are underutilized; for example, municipal solid waste contains about $85 \%$ of biomass and other combustible materials, comprising a mixture of energy-rich fuels. Likewise, coal combustion residues from power plants, such as fly ash, bottom ash, boiler slag, and flue gas desulfurization residues, can be beneficially used in concrete and cement production, structural fills, building products, gypsum wallboard, and surface stabilization. The World Economic Forum estimates that based on current technologies, the circular economy approach could save more than $\$ 1$ trillion/yr globally due to lower costs, lower carbon emissions, and supply chain risk reduction (WEF 2013). Circular economy practices include reverse logistics (eg., refurbishment of containers, pallets, used or defective products), beneficial reuse of wasted materials or energy (e.g., composting, used oil recovery, biodigestion of organics, combined heat and power), and business model innovation (eg., dematerialization, resource pooling, product-as-a-service).

A particularly effective circular economy practice is called by-product synergy (BPS), first introduced by the US Business Council for Sustainable Development and widely adopted by companies in diverse industries (Cimren et al. 2010). By collaborating across industry lines, companies can avoid landfilling costs and reduce material procurement costs by converting industrial or municipal wastes into feedstocks for other industrial processes, thus turning waste into profit. This not only contributes to long-term sustainability by reducing a company's ecological footprint, but also improves a company's resilience by reducing dependence on imported supplies and scarce resources. BPS is by far the shortest and most efficient path to achieving a circular economy. Municipal waste recovery is much more resourceintensive, and in any case, municipal waste is only a small fraction of the total solid waste generated by industry.

More broadly, taking a systems approach enables harmonization of industrial processes with natural processes, which provide industries with important ecosystem services such as flood control, pollutant absorption, and carbon (C) sequestration in terrestrial ecosystems such as soil, vegetation and wetlands (Fiksel et al. 2014). These services from nature can mitigate climate change and air pollution, restore 
soil health, enhance the quality and renewability of water resources, and generally improve the environment. Today, many progressive companies are recognizing the importance of ecosystem services to ensure the resilience of their supply chains, and are pursuing resource efficiency together with end-of-life waste minimization, recovery, and reuse (Fiksel 2015).

Circular economy design should strive to be inclusive by considering how management decisions may impact various stakeholder groups, including the poor and other underrepresented segments of society that are especially vulnerable to the health impacts of waste proliferation. Stewardship of natural capital (i.e., ecological resources) and social capital (i.e., community solidarity) will help companies to achieve profitable waste reduction or avoidance in ways that not only benefit their shareholders and business partners but also earn the respect and appreciation of public stakeholders. Thus, judicious management of all waste sources (industrial, agricultural and municipal) can advance progress toward many of the UN SDGs. In particular, circular economy practices will contribute to Goal 12 -environmentally sound management of chemicals and wastes, including reduction in releases, and Goal 3-ensuring healthy lives and well-being, including reduction in deaths and illnesses due to environmental pollution.

In the agricultural sector, best management practices such as conservation agriculture, integrated nutrient management, and sustainable intensification, i.e., producing more from less, can increase soil resilience and restore the carbon pool, providing multiple benefits-greenhouse gas sequestration, improved water quality and conservation, decreased nutrient loss, reduced soil erosion, greater crop yields, and food and nutritional security (Lal 2016). India generates an estimated 1.6 MMT per year of agricultural wastes, but a large proportion of these resources can be composted and used as soil amendments. With judicious use of chemical fertilizers, this would eliminate the nutrient deficit in agricultural soils while sequestering carbon and improving the health of soil, plants, animals, people and the environment. Agricultural wastes can also be utilized as industrial raw materials; for example, rice husk ash is a valuable industrial raw material for steel, cement, and refractory bricks, and can also be used for waste water treatment, thermal insulation, mortar and concrete production, soil amendment, and silica production. Similarly, bagasse from sugarcane can be used to generate energy.

A recent Accenture study suggested that India can unlock approximately half-a-trillion dollars of economic value by 2030 through adoption of Circular Economy business models. As shown in Fig. 2, this could be achieved by a combination of strategies-reduction in wasted material and energy resources, improved utilization of products and capital assets, product life extension, and value recovery from waste streams.

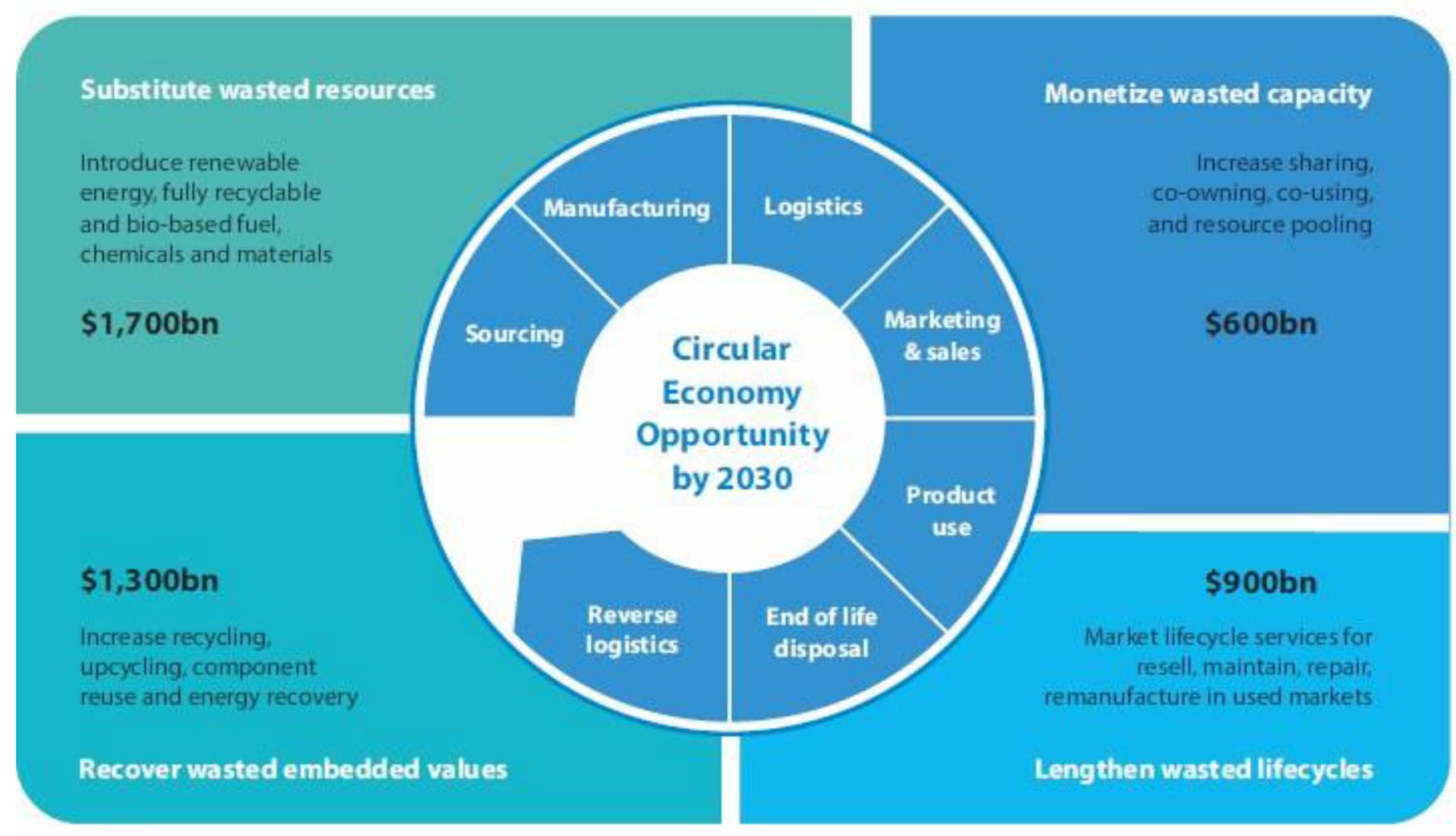

Fig. 2 Value Realization Potential from Circular Business Models by 2030 (Accenture 2019) 


\section{Case study: circular economy system for urban electronic waste}

The World Institute of Sustainable Energy (WISE) is a not-for-profit organization established in 2004, based in Pune, India. WISE is committed to the cause of promoting sustainable energy and sustainable development through the advancement of low-carbon, renewable, and energy efficient pathways that pave the way toward achieving the sustainability goals of energy security, livelihood security, and climate security. Mediating public policy through proactive interventions is the prime objective of the Institute.

This seed grant supported WISE's efforts to engage with concerned stakeholders regarding the current electronic waste (e-waste) management systems and practices in the city of Pune. The WISE team was able to identify the challenges and issues faced by the various stakeholder groups, including government authorities, civil society organizations, private entrepreneurs, citizens' groups, waste-pickers, and household consumers. Based on these insights, WISE developed a comprehensive action plan that provides practical strategies to enable a circular economy for urban e-waste management.

The electrical and electronics market in India has grown rapidly, and was projected to reach $\$ 400$ billion by 2020 (ASSOCHAM 2018). However, rapid technological obsolescence and increased consumer purchasing power have led a sharp increase in the generation of e-waste. India accounted for 2 million MT of global e-waste in 2016, ranking fourth in the world after China, the USA, and Japan. Within India, the state of Maharashtra accounted for the most e-waste generation (about 20\%). Pune is the cultural and educational capital of Maharashtra, and one of the eight largest metropolitan cities in the country. The Pune Municipal Corporation (PMC) estimated that the city generated around 16,000 MT of e-waste in 2016, of which only 8.64 MT was recycled.

Recognizing the urgent need for e-waste recycling, WISE set out to conduct a detailed study of the challenges and gaps prevalent in Pune's current e-waste management system. The objective of the study was to develop a plan for capturing at least 60 percent of e-waste generated in the next two years by enabling a circular economy system. The study methodology involved the following steps:

\section{Step 1 Current scenario assessment}

The WISE team performed an assessment of the challenges, gaps, and issues present in the e-waste management system currently present in Pune city. This included:

- Assessment of the current practices and methods adopted by the stakeholders and analysis of their effectiveness at different levels-governance, technical, financial, etc.
- Assessment of the circular economy framework for e-waste, both at the global and national level, with the objective of extrapolating best practices in the model e-waste framework for Pune city.

- Analysis of health and environmental risks associated with unscientific e-waste handling.

- Analysis of current e-waste management system and loss in value due to rudimentary techniques and improper handling of e-waste.

The WISE team spent considerable effort to characterize the e-waste regulatory regime and management practices in India (see Fig. 3). E-waste is primarily managed by civil society organizations (CSOs) and the private sector. Government legislation provides the framework for this process, and the 2018 E-waste Management Rules include Extended Producer Responsibility. The Central Pollution Control Board (CPCB), a statutory body under the Ministry of Environment, Forest, and Climate Change (MoEFCC), prepares guidelines for implementation of the e-waste rules by the respective State Pollution Control Boards. For Pune, the Maharashtra Pollution Control Board (MPCB) is the state regulatory body responsible for granting and monitoring authorizations for e-waste management. PMC is the urban civic body that governs Pune and is responsible for solid waste management in the city.

PMC currently has only a small e-waste cell. In the absence of appropriate guidelines, the role of the municipal corporation and the e-waste cell is not defined and there are no dedicated human resources for e-waste management. While the PMC has designated 177 temporary centers for collection of e-waste in the city, there is an almost complete lack of awareness among citizens regarding these centers. This has resulted in the formal sector (comprising local NGOs and private organizations) taking up the responsibility of e-waste management in the city.

However, only a handful of formal e-waste collecting and dismantling centers are currently functioning in Pune, and $95 \%$ of e-waste is managed by the informal sector (waste-pickers, known as kabadiwalas). WISE found that this group has a keen interest in being part of the formal chain and to work as licensed collectors, and expressed the need for regulatory initiatives to integrate them into the formal e-waste chain and assure them of healthy and secure work conditions.

In summary, the following are the key findings of WISE's assessment of major gaps and challenges related to e-waste management in Pune City.

- The current mandate segregates only wet and dry waste. No guidelines exist for e-waste segregation and management. 


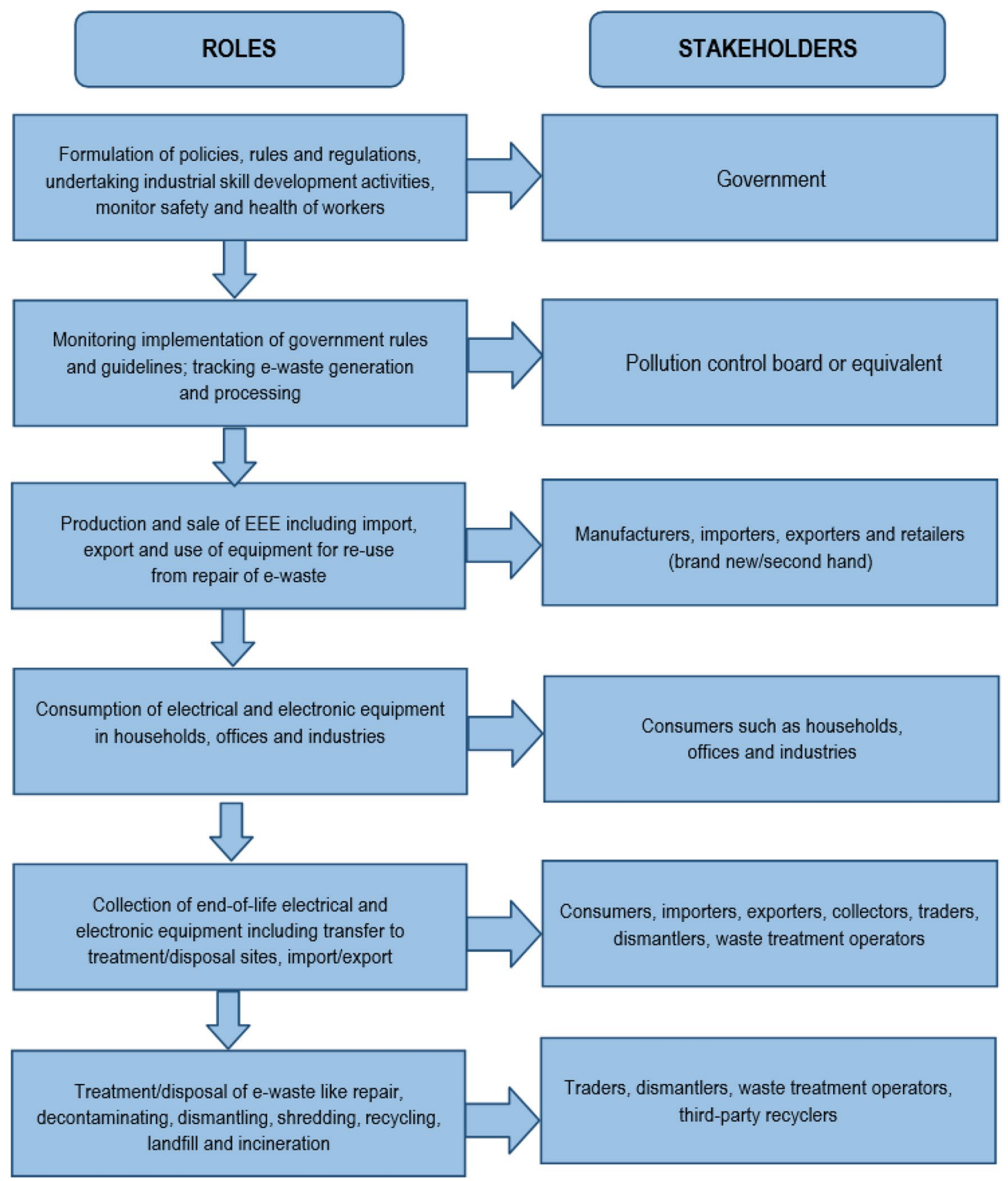

Fig. 3 E-Waste Management Stakeholder Roles in India (derived from ASSOCHAM-EY 2019)

- There are no defined baseline targets, benchmarks or timelines for e-waste management.

- No monitoring and evaluation mechanism is in place, resulting in operational inefficiency at different stages of e-waste management.

- There is a lack of proper communication and coordination among the key stakeholders, namely MPCB, PMC, and the formal sector, leading to ineffective e-waste governance and management.
- Progress is inhibited by lack of appropriate infrastructure, capacity building, and information awareness, along with lack of funding and financial incentives for the formal sector.

Step 2 Action plan preparation

Based on the findings from the above assessments, WISE proceeded to develop a Strategic Action Plan based 
on extensive engagement with key stakeholder groups. This plan includes:

- One-on-one discussions and roundtable meetings with stakeholders, comprising waste collectors, municipal authorities, NGOs, recyclers and dismantlers, established and non-established supply chain entities, and others.

- Separate interactions with domestic consumers to understand their awareness levels and expectations.

- Development of an implementation strategy and corresponding Action Plan to be carried out over the short term ( 2 years) and long term ( 5 years) by the concerned stakeholders.

Table 1 provides a detailed summary of the Strategic Action Plan. (A list of acronyms used appears at the end of the paper).

\section{Step 3 Knowledge dissemination}

The Action Plan was disseminated through a variety of channels including WISE and OSU websites, stakeholder websites, email blasts, and social media. Additionally, focus group meetings were held to ensure the feasibility of plan implementation. The final report of the WISE project has met with wide acceptability among city officials and key stakeholders across the value chain. In particular, the WISE team briefed the Joint Municipal Commissioner, Solid Waste Management, PMC and other key stakeholders, and received an enthusiastic response (see Fig. 4). It appears that the recommended Strategic Action Plan can pave the way for more informed decisions by policy-makers and e-waste chain participants, leading to development of a circular economy in Pune.

The following summarizes the strategic action recommendations that were developed in this project.

- Draft guidelines for streamlining e-waste management in Pune; prescribe rules, regulations, and penalties, if any; define stakeholder roles, and integrate these into a circular economy framework.

- Conduct a baseline study to assess and evaluate the total consumption of resources in the electronics sector and the e-waste generated, thus enabling adoption of suitable benchmarks and targets for reducing e-waste. Such a study would also be relevant for national-level targets.

- Develop a long-term resource efficiency strategy for Pune that would strive for a circular economy, reducing both virgin resource use by manufacturers and consumer consumption.

- Develop guidelines for mandating a certain percentage of recycled e-waste in manufacturing. This will enable strengthening of the formal e-waste sector (similar to the renewable purchase obligation that mandates a certain percentage of renewable energy in power purchases).

- Conduct impact assessment studies to analyze the health, environmental and economic impacts of improper e-waste recycling by the informal sector in Pune, and at a national level.

- Organize capacity building training programs and workshops (by PMC) for the formal and (especially) informal sectors, on the adverse health and environmental impacts of handling, dismantling, and recycling e-waste in an improper and unscientific manner.

- Develop appropriate business and financial models for a circular e-waste economy that would attract more funding from private institutions into the electrical and electronics sector.

- Undertake studies and organize conferences, seminars, community drives and workshops to educate citizens about the value of adopting a more sustainable lifestyle.

- Carry out feasibility studies for designing 'product service systems' that would integrate products, services, supporting networks and infrastructure, to reduce waste and form a circular economy.

- Conduct research to facilitate adoption of the "cradleto-cradle' approach, transitioning from a resource-intensive to a resource-efficient economy that decouples the environmental footprint from economic prosperity and human well-being (i.e., doing more with less for longer).

\section{Case study: waste management system for rural villages}

The Social Work and Research Centre, widely known as Barefoot College, is a voluntary organization founded by Bunker Roy in 1972. Full-time volunteers are working in the fields of education, skill development, health, drinking water, women empowerment and electrification through solar power for the upliftment of rural people.

Rural areas of India present a different set of challenges from those that exist in densely populated cities. In rural villages, there tends to be a lack of understanding of the importance of personal hygiene and proper waste disposal. The objective of this seed grant was to establish and demonstrate a low-cost, end-to-end rural solid waste management model that is designed by the local community. This model aims to ensure sanitation, environmental protection, and income and livelihood generation, and drives behavioral change in village residents by motivating them to maintain community hygiene. Thus, the project not only addresses the UN SDGs mentioned earlier-responsible consumption and human health - but also contributes to poverty elimination (Goal 1), clean water (Goal 6), and sustainable communities (Goal 11). 


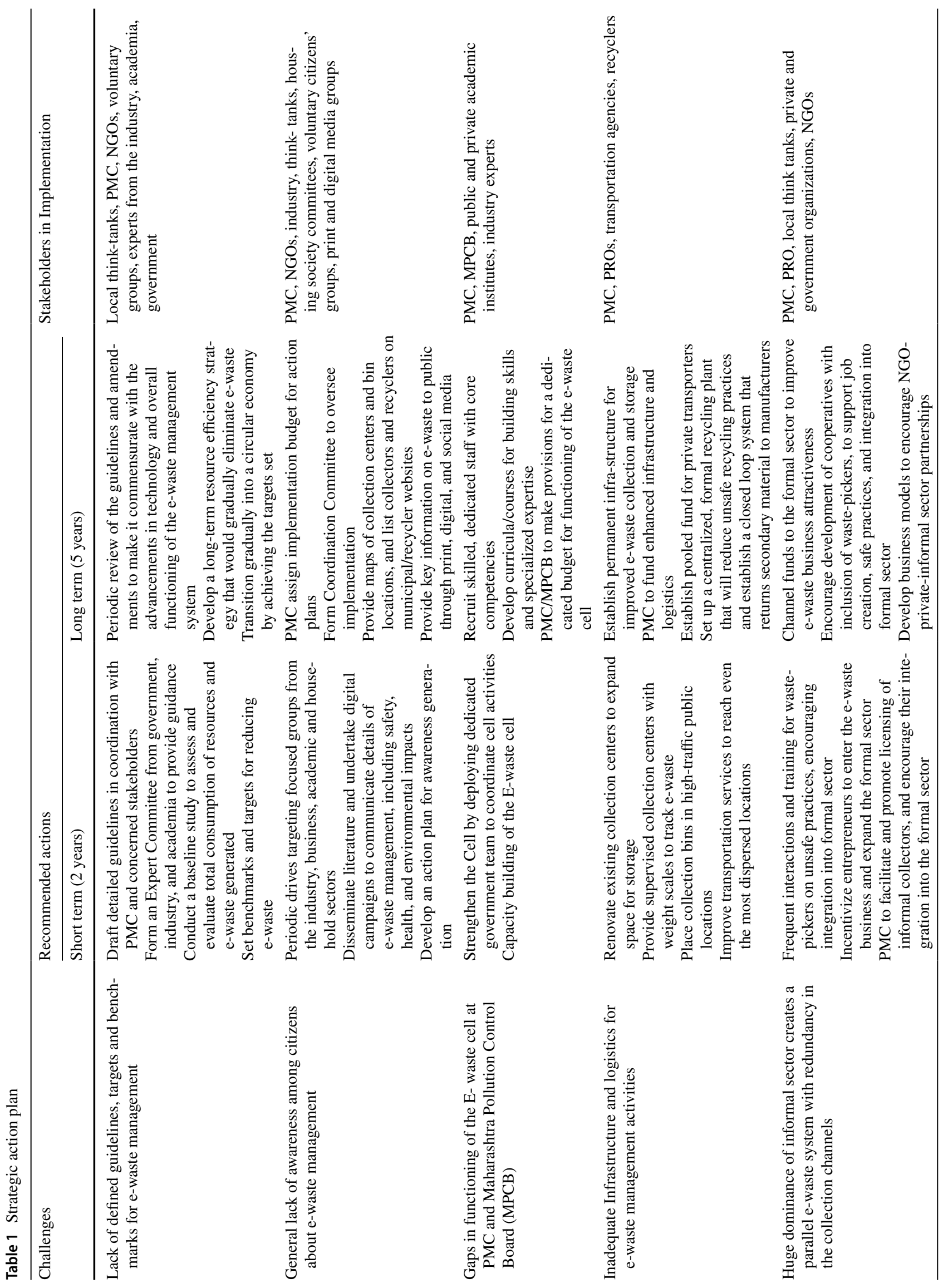




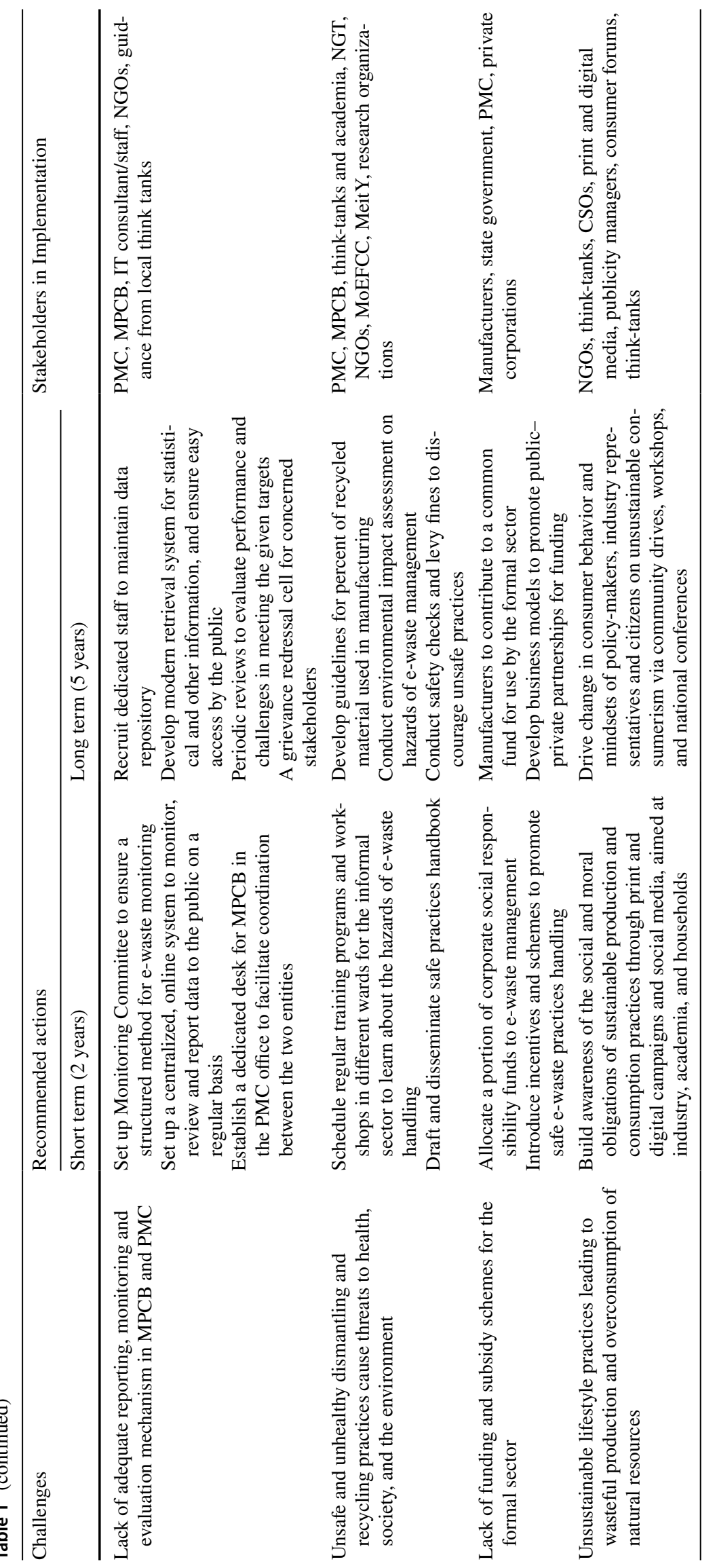




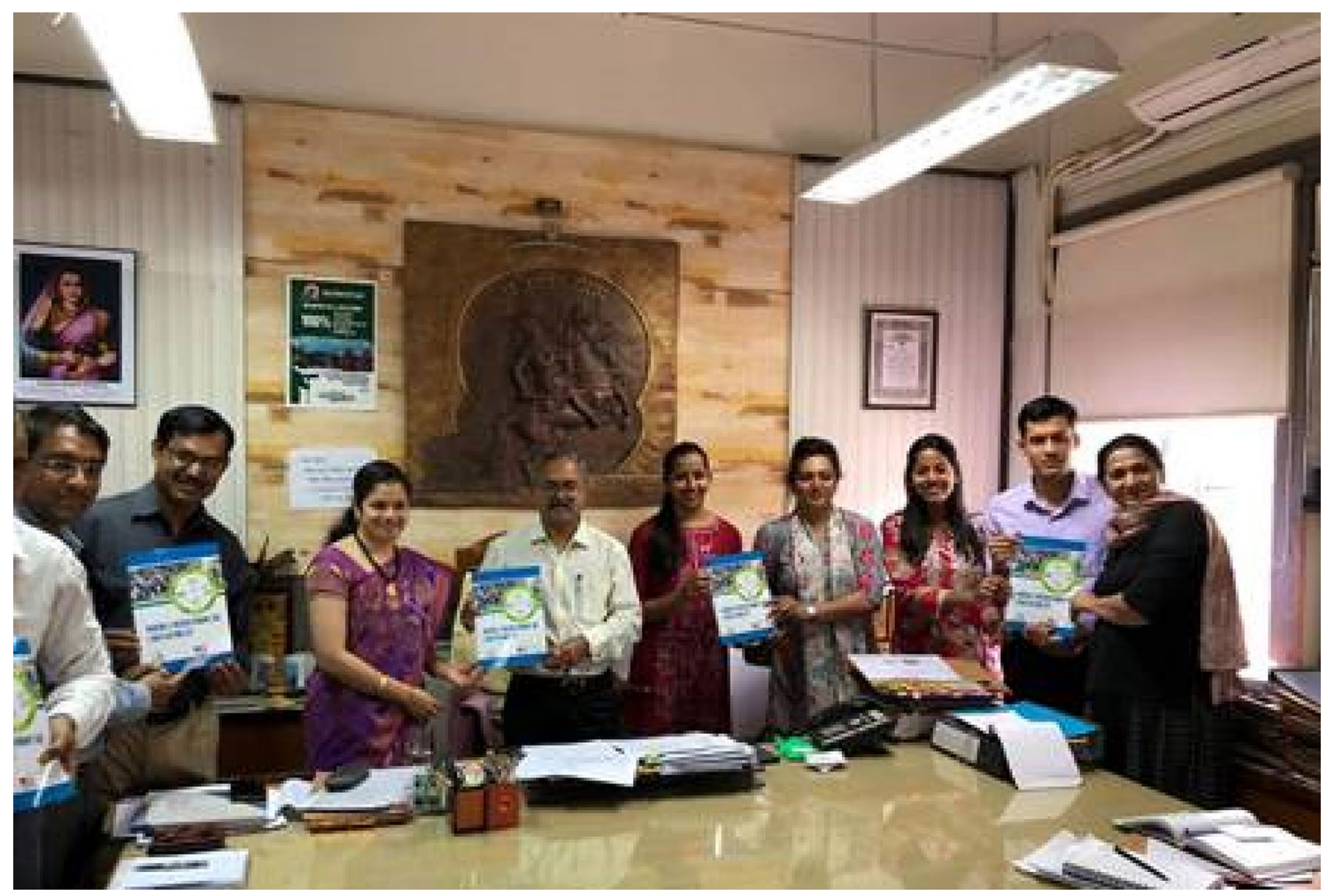

Fig. 4 Joint Municipal Commissioner, PMC (Dnyaneshwar Molak, center) launches the WISE report on "Enabling a circular economy for E-waste in Pune City" accompanied by stakeholders and WISE staff

The village selected for this project was Nalu, near the campus of Barefoot College in the Ajmer district of Rajasthan. The population consists of approximately 660 families comprising a total of 3000 residents. The major occupations of these villagers include farming, animal husbandry, marble industry, firework factories. Many are employed as contract laborers, including work supported by the National Rural Employment Guarantee Act, which aims to enhance livelihood security in rural areas by providing at least 100 days of wage employment per year to every household whose adult members volunteer to do unskilled manual work.

Drinking water, electricity, education, and basic health facilities are available in the village. However, sanitation facilities and practices are notably deficient. Although $90 \%$ of the families have toilets, only about half of these families actually use their toilets. The rest practice open defecation in the fields, a traditional practice that they find more agreeable than being shut in a small room. Moreover, the community lacks any type of waste management system, so that most trash is simply burned or discarded in nearby fields.

Baseline survey In January 2019, a baseline survey was conducted to understand the current knowledge, attitudes and practices of the community related to waste disposal and management. Each household in the village was visited to understand the general attitudes, and survey data were collected from $25 \%$ of the households. The survey results are shown in Fig. 5. Key findings were as follows:

- Existing waste disposal system While organic waste and metals are largely disposed in a non-harmful manner (composting or selling), non-biodegradable waste materials such as plastics, cloth, rubber are either dumped in the open or burned. These practices threaten the integrity of local soils and water bodies, and may endanger the health of both humans and grazing animals.

- Existing cleaning arrangements Members of the "sweeper community" are forced to clean villages for low and infrequent wages. They are a marginalized and oppressed group, treated as untouchables by the rest of the village, and are not allowed to engage in other livelihood activities.

- Interest in a waste management system All households agreed upon the need for a scientific waste management system and were prepared to support the system with a monthly contribution of Rs. 40 (about 60 cents) per household.

- Stakeholder involvement The local governance body (Panchayat), consisting of influential men and women from the community, was completely aligned with the 

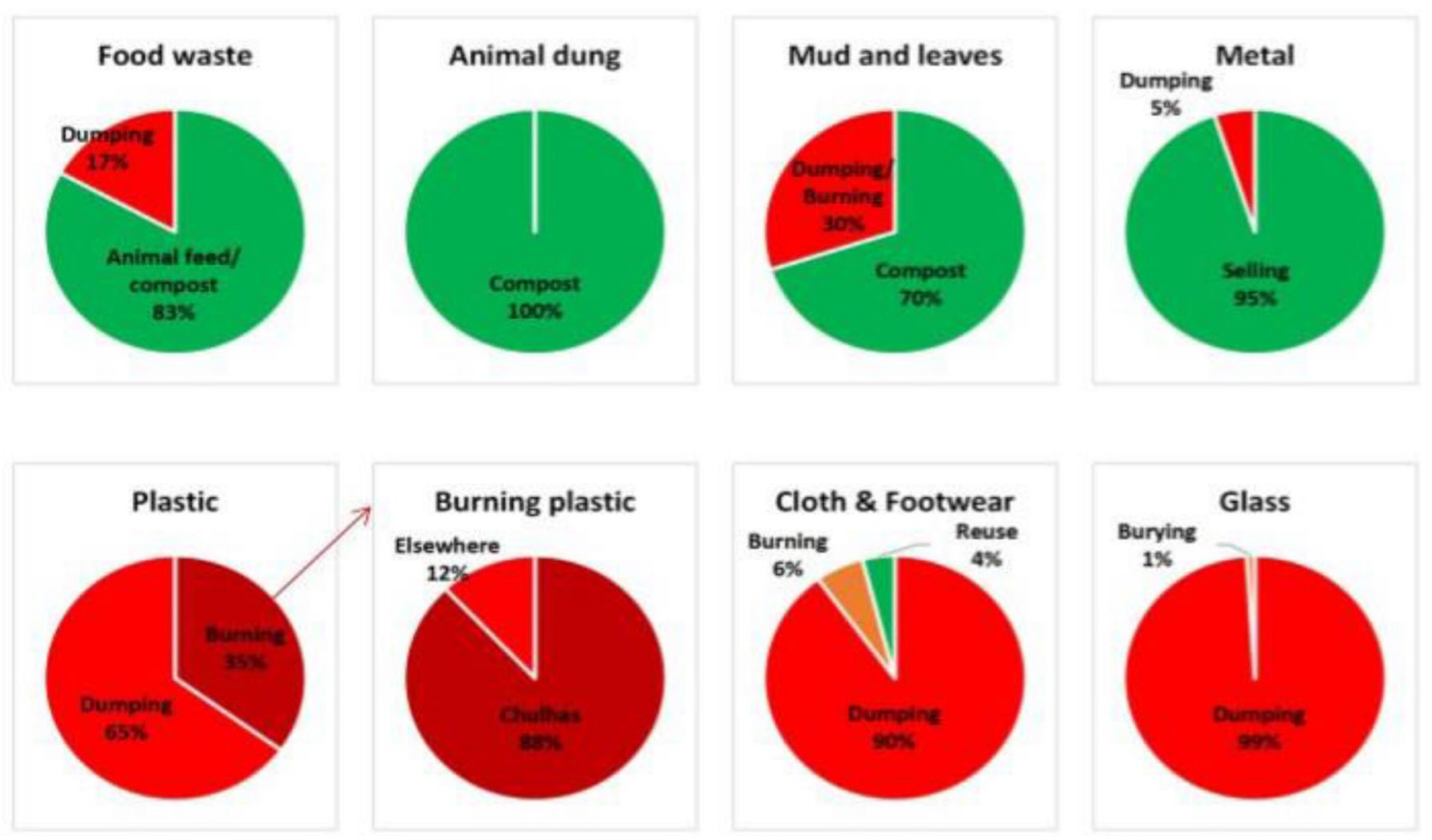

Fig. 5 Percent of Nalu households following various disposal practices for different kinds of waste

idea of setting up a waste management system in the village, and expressed support toward maintaining such a system.

System design Accordingly, the Barefoot College team set out to design a low-cost, end-to-end rural solid waste management system with the participation of the village community, illustrated in Fig. 6. The team estimated that the system would employ about 2 or 3 cleanliness workers per village, and that a supervisor would be appointed in each village. Once trained, the supervisor could most likely take responsibility for 3 or 4 neighboring villages in the region.

Implementation of this design in the village of Nalu was accomplished by the fall of 2019 , enabling the following key activities:

- Waste collection The cleanliness workers collect segregated waste from households every day. Waste is segregated into 'Organic', 'Plastic and other recyclables' and 'Hazardous' at the household level. Waste collection is accomplished using an electric-powered cart.

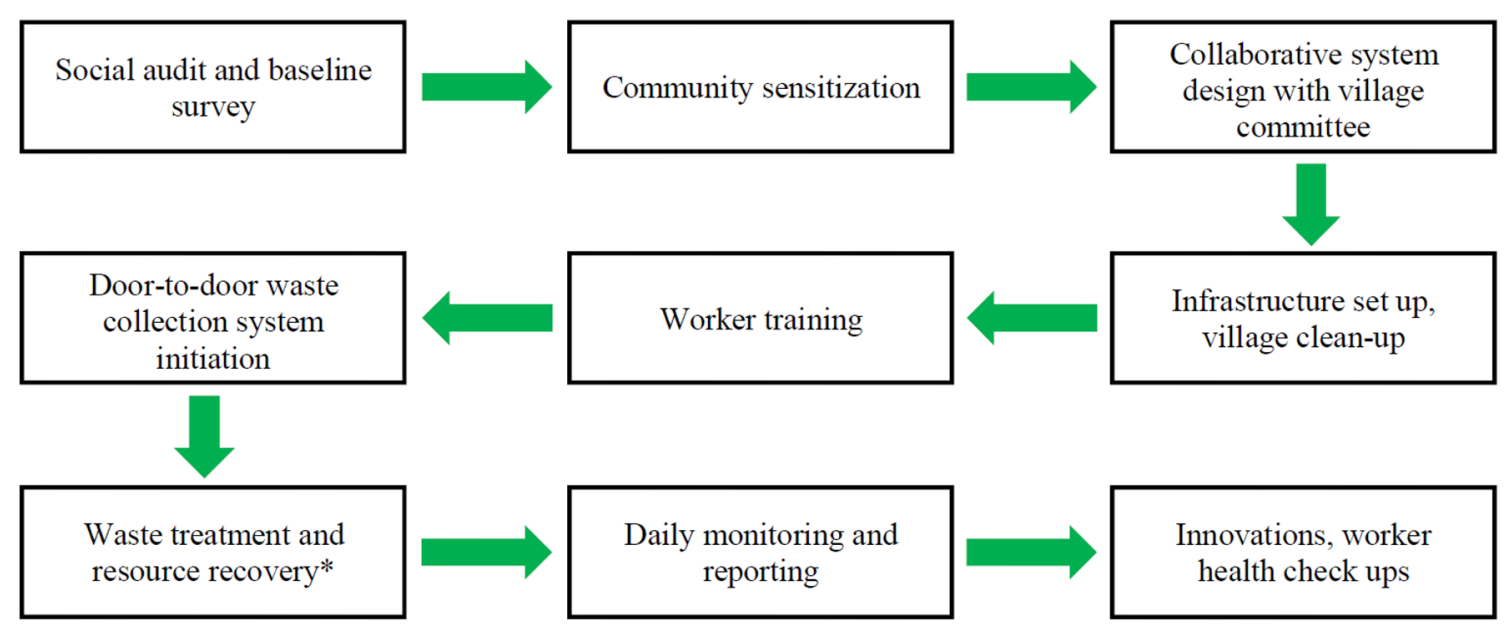

Fig. 6 Overview of the design and operation of a rural waste management system 
- Waste treatment All waste is transported to the recycling facility for processing as follows:

(a) Organic waste is converted into nutrient-rich compost through a 3-month low-cost composting technique.

(b) Recyclable waste is further segregated into plastic bottles, plastic food packaging, polyethylene bags, cloth, glass, rubber, metal, cardboard, and other materials. Each type of waste is stored separately and sold to recycling plants periodically.

(c) Bio-medical wastes such as sanitary pads, diapers, and blood-stained cloth are incinerated.

(d) Any other residual waste is sent to a sanitary landfill. After implementation of this system, less than $5 \%$ of household waste is being sent to the landfills.

(e) All the waste collected is weighed daily and documented.

- Waste value recovery Compost and recyclable waste are sold and the revenue generated is reinvested into the system to offset operational cost. A service charge is also collected from the village residents to ensure long-term ownership of the system.

Implementation of this project proceeded through the following series of steps:

\section{Step 1 Community sensitization}

February and March of 2019 were spent generating awareness of the project and sensitizing the community to the importance of waste management. Focus group discussions, mass awareness sessions using puppetry, household-level awareness generation, and randomized awareness meetings were conducted to engage the villagers in dialogue and inform them about appropriate waste management and source segregation methods. These activities included:

- Seven informal group discussions engaging 100 people

- Four ward level awareness presentations engaging 300 women

- One mass awareness puppet show engaging $>500$ residents

- Two cleaning camps in the government school involving more than 250 students

- Sensitization workshops with a village youth group (12 members) and a group of local governance officials (nine members)

As a result, almost every person in the village was made aware of the concept that was being introduced and was supportive of setting up a waste management system in the village.

Step 2 Leadership and commitment

In March 2019, an all-female village committee was formed to design, build and implement the waste management system. This approach ensures local relevance of the design as well as long-term sustainability and ownership of the system within the community. The committee mobilized residents to contribute money toward the waste management system, and was able to raise Rs 9600 (about \$640) from the local governance (Gram Panchayat), and other influential village families.

Step 3 Recycling infrastructure.

During April 2019, the team focused on setting up household infrastructure to promote source segregation. Discarded oil cans were refurbished to create visually appealing and functional dustbins. In a period of one month, more than 1000 s-hand oil cans were washed, painted and marked with 'Organic waste,' 'Plastic and other dry waste' and 'Hazardous waste.' The bins were distributed to 337 households as well as the shops, schools, and other publicly used spaces in the village. This activity had the following advantages:

- No new material was used to manufacture the dustbins, which served as a message to the community that old and discarded items can be refurbished into useful and attractive products

- The cost per dustbin was almost half of the price to purchase new dustbins of similar quality

- Five local people were given employment for 2 to 3 weeks for preparation of the bins.

Step 4 Waste treatment infrastructure.

The local governance body (Gram Panchayat) allocated land to the organization to build waste management infrastructure. From April to June 2019, the land was leveled, cleared of bushes, fenced, and made ready for construction. Four compost pits and one segregation and storage unit were constructed to treat all the waste generated by the village.

Step 5 Village clean-up

From June to August 2019, two persons from the marginalized Dalit community in the village were selected and trained to carry out the activities of sanitation workers. The two workers have taken on this role as a full-time job earning a regular salary. Through their efforts, all the traditional village dumping spots were cleared and have since remained clear of open dumping. A landfill was created to replace the existing dump sites. 
Step 6 Waste collection launch.

Beginning in July 2019, door-to-door collection was initiated using a manual cycle trolley. However, this mode of transport proved to be unsuccessful and laborious due to the many unpaved roads in the village. By September 2019, an electric three-wheeler was purchased, making waste collection much faster and easier. (See Fig. 7) More houses could be covered each day and the team had more time for segregation and treatment of the waste. Each household has been trained on source segregation, and mixed waste is not accepted from the households. Student volunteers were engaged in conducting awareness sessions with households to promote source segregation.

\section{Step 7 Waste management system}

The final step of implementation, during August to September 2019, was the establishment of an ongoing system for treatment, storage, and recycling of the collected waste. Wet waste is composted organically in aerobic NADEP (Narayan Deotao Pandharipande) method of composting, which uses a wide range of organic materials such as crop residues, weeds, forest litter and kitchen waste with an endproduct of a fertilizer that serves as a good alternative to farmyard manure. Within 3 months of filling a pit, the pit can be emptied and the compost can be used in fields. Dry waste is segregated and stored under different categories-plastics, cardboard, glass, metal, cloth, etc.—for eventual recycling.

\section{Step 8 Ongoing operation and monitoring.}

During the final months of the project, the operation of the waste management system was closely monitored by Barefoot College and a village-level supervisor. An ongoing process is being developed for supervision of the continued operation and maintenance of the system, including maintenance of the resource recovery site and overall performance tracking.

In summary, this project was successful despite numerous challenges, including the following:

- Waste management and community hygiene are not a priority for village residents; hence, it is difficult to support such systems solely through community contributions.

- Initially, the District Administration did not provide any support for this project. There was a month's delay in obtaining the necessary documents for land allocation toward the project, which delayed the setup of infrastructure.

- Existing waste in various dumping spots around the village was an ongoing hazard, since it could not be treated or recycled.

- Extreme weather conditions and the 2019 heat wave in Rajasthan resulted in fewer working hours per day; the team was able to work only during early morning and late evening hours.

Notwithstanding these challenges, the project demonstrated the feasibility of establishing a low-cost, communitydriven waste management system in rural villages within the space of one year. The beneficial impacts of this work can be summarized as follows.

- Environmental protection All dumping areas in the village have been cleared, thus preventing animals from eating plastic and other non-biodegradable waste littered on the streets. Clogged drains have been cleared of waste. Water bodies, soil, and ground water are no longer pol-
Fig. 7 Villagers bring full dustbins to the waste collection truck

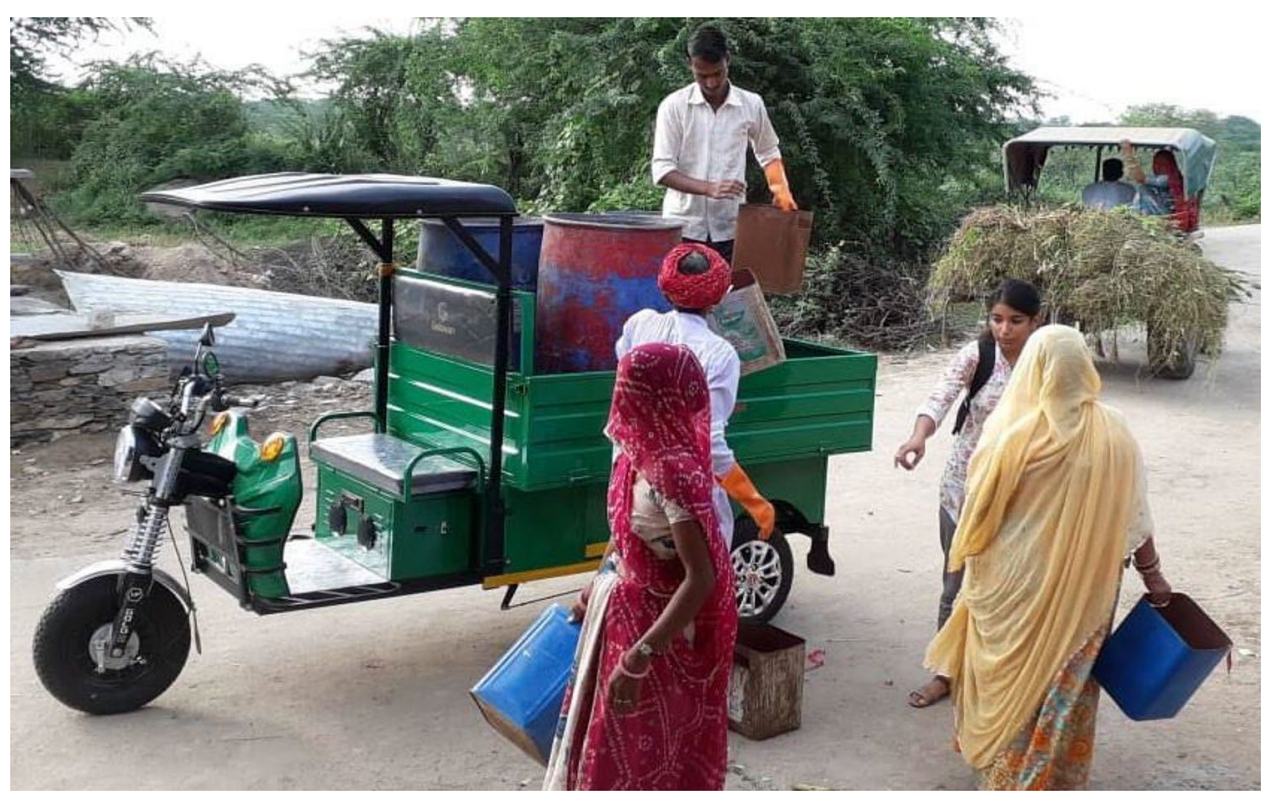


luted by toxic non-biodegradable waste, making the village hygienic and safe for living.

- Behavioral change The 3000 village residents, including men, women and children, have been sensitized regarding appropriate waste disposal and management. Almost all households practice source segregation and have ceased dumping and burning waste in the open.

- Livelihood generation Two persons from the village have been employed as cleanliness workers, earning a regular income and considering themselves as members of a dignified occupational group with high social impact.

- Value recovery from waste In the space of 4 months, over $1000 \mathrm{~kg}$ of wet waste were converted to organic compost that is being used to nourish farmers' soil. Approximately, $50 \mathrm{~kg}$ of dry waste have been segregated and diverted from landfills.

- Broader awareness Many neighboring villages have learned about this waste management model and are now demanding that it be set up in their communities as well. The Sub-Divisional Magistrate and Block Development Officer visited the waste management site and have expressed interest in funding replication of this project in other villages.

It is important to ensure that these benefits are enduring over time, and that villagers do not revert to their previous unhygienic practices. Monitoring of the waste management system is currently being performed by the Barefoot College team and the village committee representatives. The longterm aim is to fully transition the supervision of the system to the local governance authorities in order to ensure continuity and sustainability. The Barefoot College team plans to reevaluate the impact of the program after 3 years, so that they can better understand and document the impacts of the waste management system on environmental and social parameters.

\section{The path forward}

The conference on Waste Management Innovation and the subsequent seed grants resulted in a number of useful insights and recommendations, which are summarized below.

- Based on circular economy principles, urban and agricultural wastes can be repurposed as industrial resources. There are a variety of proven methods and technologies available, ranging from centralized waste collection and processing to decentralized applications that could function at a neighborhood or individual household scale.

- Circular economy advances will not only improve the resilience of urban and agricultural economies in the face of turbulent change, but also will deliver benefits including climate mitigation, food and water security, enhanced biodiversity, job creation, and empowerment of underprivileged communities.

- Innovations in design and communication are necessary to induce behavior change, ranging from recycling of trash to the use of toilets rather than open defecation. Customized strategies are needed due to the vast differences between rural villagers and urban populations.

In order to advance toward a circular economy, changes in policy are needed to stimulate technological innovation and waste management improvements. The Swach Bharat Mission represents a major step forward in raising consciousness and investing in cleaner practices. Indian industries and municipalities have shown that they can benefit from borrowing global best practices and proven approaches that provide benefits in terms of public health, sanitation, energy supply, water and land protection, and of course cost savings.

There are a variety of instruments available to governments in order to accelerate adoption of circular economy principles. These include regulatory requirements, marketbased incentives such as subsidies, taxes, or cap and trade schemes, payments for enhancement of essential ecosystem services such as recarbonization of soil, and information campaigns to encourage voluntary initiatives.

A number of policy-based initiatives were recommended by an expert panel that examined the potential for circular material and energy flows across key sectors of the Indian economy, including automotive, electronics, and construction. (India Resource Panel, Ministry of Environment, Forests and Climate Change 2016) The panel noted a need to improve the design and implementation of circular economy approaches, and offered a variety of policy recommendations, including:

- Product eco-labeling schemes to disclose recycled content and other environmental benefits

- Tax incentives to stimulate the use of greener and cleaner product and process technologies

- Design standards that include resource efficiency and use of secondary raw materials

- Standard business models and financial mechanisms for end-of-life product recovery

- Social innovations that support sharing, renting, leasing or pooling of products

- Special Economic Zones providing incentives for establishment of recycling capabilities

- Preferential "green" procurement schemes based on criteria or approved product lists

- Raising consumer awareness through campaigns in print, broadcast, and social media 
- Stakeholder consultations on policy implementation experiences and possible improvements

Stimulation of voluntary compliance and innovation will be critical to the future success of waste management and circular economy programs. The systems approach suggested in this paper can provide a holistic framework for understanding the challenges, opportunities, and benefits associated with various social, environmental, and industrial initiatives. Hopefully, this will lead to a coordinated portfolio of policies that will reduce waste proliferation and enable sustainable growth of the Indian economy.

In summary, enlightened policies provide a foundation for change, but successful policy implementation will require stimulus for innovative demonstration programs at the local and regional level. The seed grants described here are examples of initiatives that show the practical feasibility of circular economy approaches and develop community commitment through active engagement of stakeholders.

Acknowledgements The authors wish to thank Neha Tiple and Debarshi Gupta of WISE, who co-authored several sections of this report. We are grateful to the US Consulate General, Mumbai, for funding the 2017 conference and the subsequent seed grants, especially the efforts of Tasneem Kalsekar and Tejaswini Karalkar. We also thank the Ohio State University (OSU) staff who supported the seed grants, including the contract officer, Geetha Sampathkumar and the director of the OSU Mumbai Gateway Office, Nikhil Tambe. Finally, we wish to acknowledge the contributions of the entire WISE Project team in Pune, as well as the many volunteers at Barefoot College who supported development of a rural waste management system.

\section{References}

Accenture and Federation of Indian Chambers of Commerce and Industry (FICCI) (2019) Accelerating India's circular economy shift
Associated Chambers of Commerce and Industry of India (ASSOCHAM), NEC Technologies India (NECTI) (2018) Electrical and electronics manufacturing in India

Associated Chambers of Commerce and Industry of India (ASSOCHAM), Ernst and Young (EY), Consumer Electronics and Appliances Manufacturers Association (CEAMA), Association of Public-Safety Communications Officials (APCO) (2019) E-waste in India: the Big "W" impact

Cimren E, Fiksel J, Posner ME, Sikdar K (2010) Material flow optimization in by-product synergy networks. J Ind Ecol 15(2):315-332

Ellen MacArthur Foundation (2017) What is a circular economy? https://www.ellenmacarthurfoundation.org/circular-economy. Accessed 23 Dec 2017

Fiksel J (2011) Design for environment, 2nd edn. A guide to sustainable product development, McGraw-Hill, New York

Fiksel J, Bruins R, Gatchett A, Gilliland A, ten Brink M (2014) The triple value model: a systems approach to sustainable solutions. Clean Technol Environ Policy 16(4):691-702

Fiksel J (2015) Resilient by design: creating businesses that adapt and flourish in a changing world. Island Press, Washington, DC

Fiksel J, Lal R (2018) Transforming waste into resources for the Indian economy. Environ Dev 26:123-128

India Environment Portal (2016) Solid waste management rules. https ://www.indiaenvironmentportal.org.in/content/427824/solid-waste -management-rules-2016/. Accessed 25 July 2020

Lal R (2013) Soil and Sanskriti. J Indian Soc Soil Sci 61:267-274

Lal R (2016) Feeding 11 billion on 0.5 billion hectare of land area under cereals. Food Energy Secur J 5(4):239-251

Ohio State University (OSU) (2017). In: Conference proceedings. https ://u.osu.edu/wastemanagementinnovation/

U.N. 2015 (2015) Sustainable development goals for people and planet. U.N. Department of Public Information, United Nations, S-108, New York, NY 10017, USA

World Economic Forum (WEF) (2013) Towards the circular economy: accelerating the scale-up across global supply chains

Publisher's Note Springer Nature remains neutral with regard to jurisdictional claims in published maps and institutional affiliations. 